were clinically normal. Two days later she lost the vision in the lower half of the right visual field and the right optic disc was swollen. Haemoglobin was $81 \%$; erythrocyte sedimentation rate 60, I $\mathrm{I}^{131}$ uptake $84 \cdot 6 \%$ at 24 hours, and $\mathrm{T}-4$ dialysate $1 \cdot 12 \%$ (normal $0 \cdot 46-0 \cdot 80 \%$ ). Biopsy of the temporal artery showed giantcoll arteritis. She responded to treatment with prednisone and radioiodine.

Case 2.-A 62-year-old woman developed painful temporal

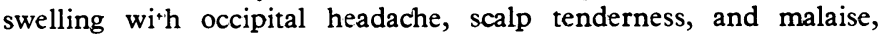
which subsided in a month. One month later she suffered weight loss, intolerance of heat, sweating, and diarrhoea. She was clinically thyrotoxic with a score of 20 on the Wayne Clinical Index. The temporal arteries were clinically normal. On investigation protein bound iodine was $19.6 \mu \mathrm{g} / 100 \mathrm{ml}$ (normal 4-8 $\mu \mathrm{g} / 100 \mathrm{ml}$ ) and the erythrocyte sedimentation rate 123 . Temporal artery biopsy confirmed the diagnosis of giant-cell arteritis and treatment with prednisone $40 \mathrm{mg} /$ day was started. Six days later the $I^{131}$ uptake was $26 \%$ at four hours, the P.B.I. $8.3 \mu \mathrm{g} / 100 \mathrm{ml}$, and the T-3 binding coefficient $256 \%$ (normal $92-120 \%$ ). Thyroid antibodies were not present. Though this indicated hyperthyroidism no additional therapy was given. Five weeks later she appeared euthvroid, with a Wayne Clinical Index score of 8, P.B.I. 50 $\mu \mathrm{g} / 100 \mathrm{ml}$, and $\mathrm{T}-3$ binding coefficient $106 \%$. We concluded that she had a spontaneous remission of thyrotoxicosis or that it was suppressed by corticosteroid treatment (Werner and Platman, 1965).

\section{Discussion}

Many large series of cases of giant-cell arteritis have been reported but in most there is no mention of associated diseases (Hamilton et al., 1971). In a report of cases from the Mayo Clinic (Hauser et al., 1971), however, four of the 19 patients had previously had a thyroidectomy for goitre but there is no mention of thyroid dysfunction. There is a close link between giant-cell arteritis and polymyalgia rheumatica, and in a study of 94 cases of these diseases Fauchald et al. (1972) claimed that there was no clear difference between them. They also reported a case of a woman who presented with a simultaneous onset of hypothyroidism and polymyalgia rheumatica. Niarchos and Finn (1973) reported an association between hypothyroidism and abdominal aneurysm and suggested that the arterial disease was due to an immunological disorder affecting the aorta.

An association of two diseases, particularly with a simultaneous onset, may indicate a common cause. The evidence for an autoimmune basis for thyrotoxicosis is considerable (Werner et al., 1972) and it has been associated with many other diseases thought to be autoimmune. Giant-cell arteritis is also considered to be a disease of altered immunity (Sandok, 1972). That it should be associated with thyrotoxicosis is therefore not entirely unexpected. This association has clinical relevance and adds to other indirect evidence that giantcell arteritis is caused or perpetuated by an abnormal immune mechanism.

We thank Dr. B. Creamer for allowing us to report clinical details of two patients and Mr. A. Swan for statistical help.

\section{References}

Birkhead, N. C., Wagener, H. P., and Shick, R. M. (1957). Fournal of the American Medical Association, 163, 821.

Crooks, J., Murray, I. P. C., and Wayne, E. J. (1959). Quarterly fournal of Medicine, 28, 211.

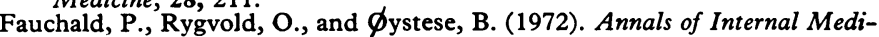
cine, $77,845$.

Hamilton, C. R., Shelley, W. M., and Tumulty, P. A. (1971). Medicine,

50, 1 W. A., Ferguson, R. H., Holley, K. E., and Kurland, L. T. (1971). Mayo Clinic Proceedings, 46, 597

Niarchos, A. P., and Finn, R. (1973). British Medical Fournal, 4, 110.

Sandok, B. A. (1972). Fournal of the American Medical Association, 222, 1405. Sandok, B. A. (1972), Fournal of the American Medical Associat

Werner, S. C., Wegelius, O., Fierer, J. A., and Hsu, K. C. (1972). Nerv England fournal of Medicine, 287, 421 .

\title{
Alpha-chain Disease with Clinical, Immunological, and Histological Recovery
}

\author{
O. N. MANOUSOS, J. C. ECONOMIDOU, D. E. GEORGIADOU, \\ K. G. PRATSIKA-OUGOURLOGLOU, S. J. HADZIYANNIS, \\ G. E. MERIKAS, K. HENRY, W. F. DOE
}

British Medical fournal, 1974, 2, 409-412

\section{Summary}

Clinical, immunological, and histological recovery in a patient with alpha-chain disease is described. The patient, a 27-yearold Greek man, presented with severe steatorrhoea, abdominal pain, oedema, and hypogammaglobulinaemia. Treat-

Second Medical Department of Athens University Medical School, Hippokration General Hospital, Athens, Greece

O. N. MANOUSOS, M.D., PH.D., Assistant Prcfessor of Medicine J. C. ECONOMIDOU, M. D., PH.D., Assistant Professor of Medicine J. C. ECONOMINOU, M. D., PH.D., Assistant Professor of Med

G. E. MERIKAS, M. D., Professor of Medicine

University of Athens, Athens, Greece

D. E. GEORGIADOU, M.D., Assistant Professor of Pathology

Department of Pathology, Hippokration General Hospital, Athens, Greece

K. G. PRATSIKA-OUGOURLOGLOU, M.D., Head of Department

Royal Postgraduate Medical School, Hammersmith Hospital, London W12 0HS

K. HENRY, M.R.C.P., Lecturer in Histopathology

W. F. DOE, M.SC., M.R.C.P., Lecturer in Medicine ment with tetracycline produced only temporary remission. Intermittent therapy with prednisone and cyclophosphamide together with antibiotics was followed by clinical recovery, return of histological appearances of the small intestine to normal, and disappearance of free alpha-chain protein from the serum. The patient remained well one year later without treatment.

\section{Introduction}

Alpha-chain disease was first described by Seligmann et al. (1968). They reported the presence of a heavy chain fragment of $\operatorname{IgA}$, free of light chains, in the serum, urine, and jejunal fluid of a patient suffering from so-called "Mediterranean lymphoma," a disease now known to occur in populations of diverse geographic and ethnic origins (Seligmann et al., 1971; Novis et al., 1971; Doe et al., 1972). Alpha-chain disease affects young patients and is characterized clinically by diarrhoea, abdominal pain, and finger clubbing. Histologically there is diffuse, predominantly plasma cell, infiltration of the wall of the small intestine.

Little is known about natural history and response to therapy in this condition. While remission has been achieved 
using antibiotic therapy alone (Rogé et al. 1970) most patients have been treated with alkylating agents, corticosteroids, and antibiotics, and after initial remissions, sometimes lasting several years the mononuclear infiltrate has become frankly malignant, resulting in death from disseminated lymphoma (Bognel et al., 1972; Doe et al., 1974).

This report describes a sustained and apparently complete clinical, histological, and immunological recovery in a Greek man suffering from alpha-chain disease after treatment with antibiotics, intermittent cyclophosphamide, and prednisone. The patient, whose presenting features have been previously reported (Doe et al., 1972), remained well three years after the diagnosis of his disease and one year after stopping all therapy.

\section{Methods}

Biopsies.-Peroral intestinal biopsy specimens were taken from beyond the ligament of Treitz using a modified Crosby capsule and processed and stained using standard techniques. Two biopsies were also processed for electron microscopy.

Immunofluorescence.-Cryostat tissue sections, $5 \mu \mathrm{m}$ thick, were stained using fluorescein (FITC) conjugated rabbit antihuman IgG, IgA, and IgM (Hyland Laboratories).

Protein Studies.-Electrophoresis was carried out on cellulose acetate strips and immunoelectrophoresis by the highvoltage method of Wieme (1965). Serum immunoglobulins were estimated using a radial immunodiffusion method (Mancini et al.. 1965). Immunoselection plates as described by Doe et al. (1972) were used to detect free alpha-chain protein in serum, concentrated saliva, jejunal fluid, and urine.

Lymphocyte Studies.-Peripheral blood lymphocytes were incubated with phytohaemagglutinin (Difco), and percentage blast transformation was assessed morphologically after $\mathbf{7 2}$ hours' culture (normal range $46-91 \%$ ). Blast transformation after six days' incubation with old tuberculin $(1 / 2,000)$ was also tested. More than $3 \%$ blast transformation was considered positive (normal spontaneous transformation range $0-1.9 \%)$.

\section{Case Report}

The patient was a 27-year-old Greek waiter who developed diarrhoea in 1967. The next year stool examination showed giardiasis, but a course of mepacrine therapy produced only temporary improvement. Six months later diarrhoea recurred, he developed abdominal pain, and he began to lose weight. In April 1970 he was admitted to hospital in Athens, where he was found to be emaciated, with ankle oedema and appreciable finger clubbing. Sigmoidoscopic examination showed diffuse inflammation of the rectal mucosa, which presented a nodular appearance. Haemoglobin white cell count, E.S.R., and bone marrow were normal, but serum albumin $(2.6 \mathrm{~g} / 100 \mathrm{ml})$ and potassium $2.8 \mathrm{mmol} / 1$.) were low. The glucose tolerance test showed a flat curve and there was malabsorption of D-xylose, only $2.5 \mathrm{~g}$ of a $25-\mathrm{g}$ oral loading dose being excreted in five hours. When radioactive vitamin $B_{12}$ was given orally with intrinsic factor only $4 \%$ of the oral dose was excreted in 24 hours (normal $>10 \%$ ). Faecal fat was appreciably increased $(44 \mathrm{~g} / 24 \mathrm{hr}$; normal $<5 \mathrm{~g}$ ). The results of stool examination were repeatedly negative for ova, cysts, and parasites.

Barium studies of the gastrointestinal tract showed normal appearances of the stomach and colon, but the small intestine was abnormal. Loops of small intestine were dilated, the mucosal folds were coarse, and a diffuse nodular appearance was seen. The jejunal biopsy specimen was also markedly abnormal. There was a considerable reduction in villious height, a well preserved epithelium, crypt sparsity, and a very dense cellular infiltrate of the lamina propria, consisting mainly of immature lymphoid and plasma cells. A rectal biopsy specimen showed diffuse infiltration of the mucosa and submucosa with plasma cells.

Electrophoresis of serum showed a broad protein band extending from alpha into the beta region and reduced gammaglobulins.
Serum immunoglobulin estimations showed severe hypogammaglobulinaemia, especially affecting the IgG and IgM classes (IgG $190 \mathrm{mg}$, IgM $14 \mathrm{mg}$, IgA $66 \mathrm{mg} / 100 \mathrm{ml}$ ). Fluorescent labelled antibody studies of the jejunal mucosa showed virtual absence of IgA-containing cells. There was a deficient antibody response after immunization with $\mathrm{TAB}$, but lymphocyte responses to stimulation by phytohaemagglutinin ( $70 \%$ blast transformation) and purified protein derivative were normal $(6 \%$ blast transformation).

There was no response to a gluten-free diet over a two-month period, and because of the hypogammaglobulinaemia and d:arrhoea oral tetracycline ( $1 \mathrm{~g}$ daily) was given. There was a striking but temporary symptomatic improvement and his weight increased by $3 \mathrm{~kg}$ (fig. 1). Sigmoidosoopic appearances of the rectal mucosa returned to normal. Subsequently non-absorbable sulphonamides ( $3 \mathrm{~g}$ daily) and oral prednisone ( $15 \mathrm{mg}$ daily) were given but prednisone therapy was stopped six weeks later after haematemesis due to an acute gastric ulcer. For the next six months the gluten-free diet was continued together with a variety of oral broad-spectrum antibiotics and folic acid. During this period his weight improved initially but then decreased, and diarrhoea and abdominal pain continued. In March 1971 there was a rapid deterioration in the patient's condition. Abdominal pain. weight loss, and diarrhoea increased and ankle swelling doveloped followed by polyuria and vomiting. At this stage the patient was referred to Hammersmith Hospital, London.

Clinical examination showed a wasted man (weight $46 \mathrm{~kg}$ ) with signs of peripheral oedema and marked clubbing of the fingers and toes. At this time sigmoidoscopic appearances of the rectal mucosa were normal.
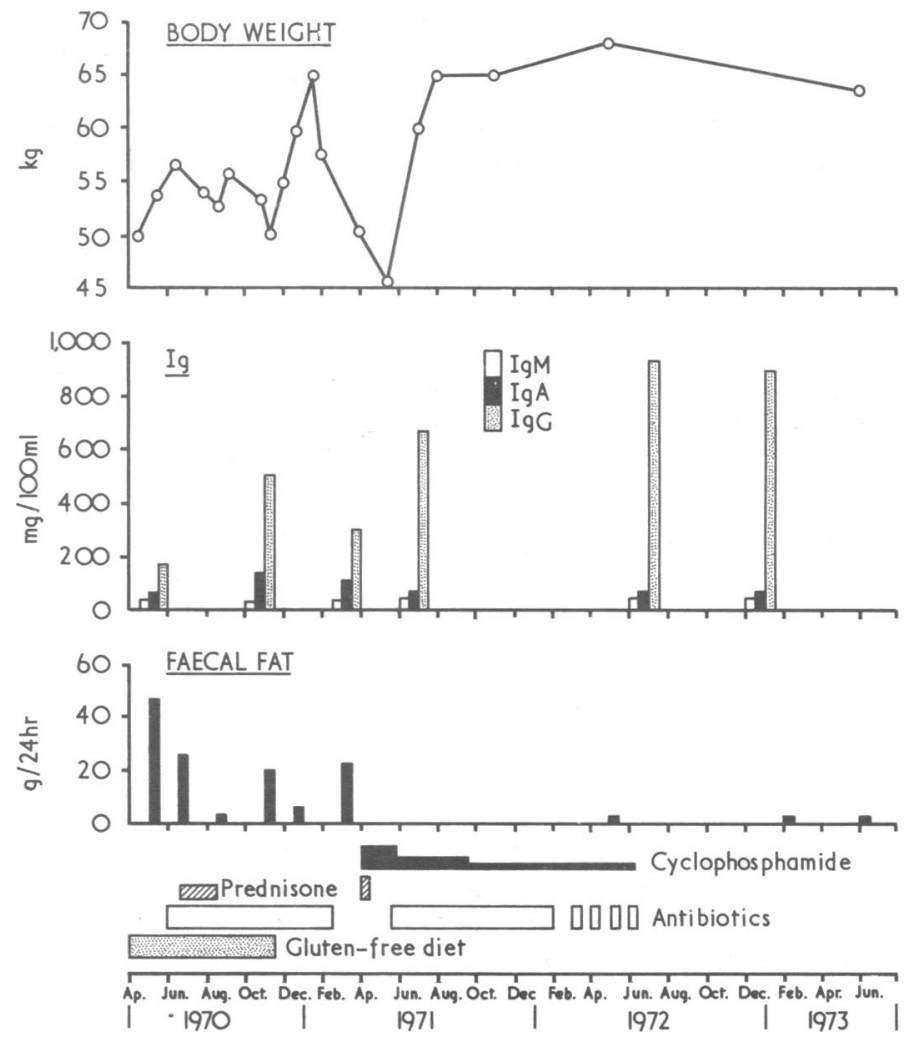

FIG. 1-Effects of treatment on body weight, serum immunoglobulin levels, and daily faecal fat excretion.

\section{INVESTIGATIONS}

Haema'ology.-Haemoglobin was $15.0 \mathrm{~g} / 100 \mathrm{ml}$, white blood cells were 7,100 per $\mathrm{mm}^{3}, 8 \%$ being abnormal plasma cells. Results of bone marrow examination were normal. E.S.R. was increased ( 31 $\mathrm{mm}$ at 1 hour) and serum iron was low $(30 \mu \mathrm{g} / 100 \mathrm{ml})$. Serum vitamin $B_{12}$ was normal $(752 \mathrm{pg} / \mathrm{ml})$ and the serum folate was $23.4 \mathrm{ng} / \mathrm{ml}$.

Biochemistry.-Serum electrolytes were as follows: Na 146 mmol, K $2.2 \mathrm{mmol}$, and bicarbonate $20 \mathrm{mmol} / 1$. Serum calcium 
was $4.4 \mathrm{mmol} / 1$., inorganic phosphate $1.0 \mathrm{mmol} / 1$, and magnesium $1.0 \mathrm{mmol} / 1$, and the alkaline phosphatase was raised to $28 \mathrm{~K}$.A. units (normal 3-13), mainly due to an increase in the bone type isoenzyme. There was hypo-albuminaemia $(2.9 \mathrm{~g} / 100 \mathrm{ml})$ with a total serum globulin of $2 \cdot 1 \mathrm{~g} / 100 \mathrm{ml}$.

Absorption Tests.- There was malabsorption of D-xylose, only $2.5 \mathrm{~g}$ of the $25-\mathrm{g}$ loading dose being excreted in five hours (normal $>5 \mathrm{~g} / 5 \mathrm{hr}$ ). In addition, when labelled vitamin $B_{12}$ was given with intrinsic factor only $1 \%$ of the dose was excreted in 24 hours (normal $>10 \%$ ). Faecal fat was markedly increased at $21.4 \mathrm{~g} /$ day during a six-day balance study. Results of stool examination were repeatedly negative for ova, cysts, and parasites.

Radiology.-Barium studies of the gastrointestinal tract showed no abnormality of the oesophagus or stomach, but the small intestinal pattern was grossly abnormal showing hypertrophied mucosal folds with a diffuse nodular pattern. There was also narrowing of a short segment of small intestine. Barium enema showed a coarse mucosal pattern with wide separation of mucosal folds.

Histology.-Jejunal biopsy specimens showed the distinctive appearances associated with alpha-chain disease, the basic mucosal abnormalities being a massive and diffuse mononuclear cell infiltrate of the lamina propria with resulting distortion of villous architecture and crypt sparsity (fig. 2). The surface epithelium was relatively normal. The cellular infiltrate consisted predominantly of plasma cells (fig. 3 ) with a significant proportion of cells intermediate in type between lymphocytes and plasma cells-a feature confirmed on ultrastructural study. A rectal biopsy specimen showed an increase in lymphocytes and plasma cells but was otherwise normal.

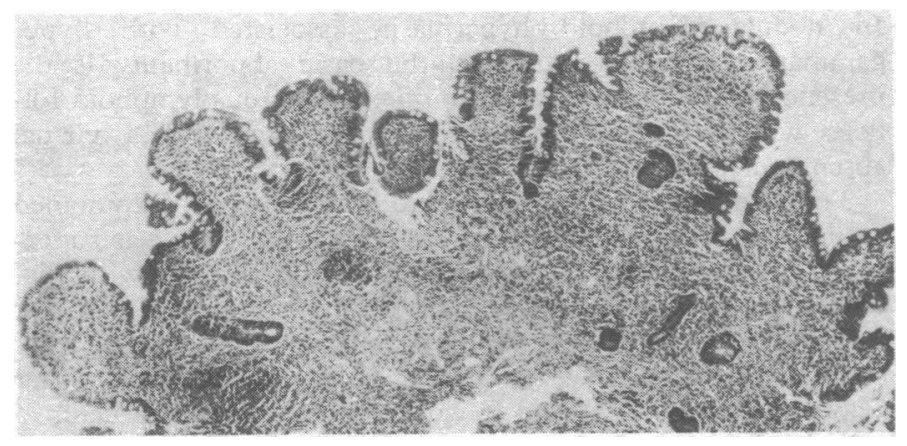

FIG. 2-Jejunal biopsy specimen showing broad distorted villi, crypt sparsity, and a dense cellular infiltrate. ( $\times 37$ ).

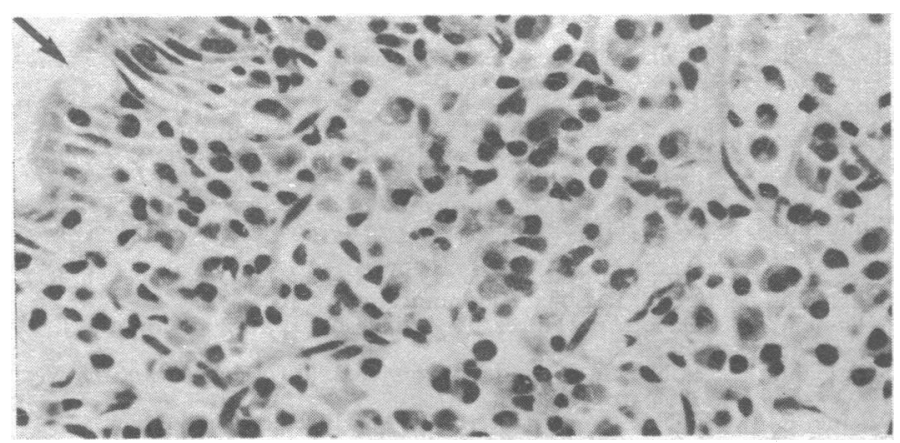

FIG. 3-Cellular infiltrate composed predominantly of plasma cell series. Fote relative normality of overlying epithelium (arrowed). ( $\times 305)$.

Protein Studies.-Electrophoresis of serum showed increased alpha-1, alpha-2, and beta globulins and a decreased gammaglobulin band. Serum immunoglobulin estimation showed severe hypogammaglobulinaemia, IgG and IgM levels being the most affected (IgG $310 \mathrm{mg}$, IgM $21 \mathrm{mg}$, IgA $103 \mathrm{mg} / 100 \mathrm{ml}$ ). When immunoelectrophoresis of serum and concentrated urine was carried out a protein reacting with anti-IgA antiserum but having abnormally fast mobility was detected in both serum and urine. Immunoselection plates showed alpha-chain protein, free of light chains, in serum, saliva and concentrated urine and jejunal fluid. This alpha-chain protein showed a reaction of identity with alpha-chain protein of known subclass alpha-1. These findings were characteristic of alpha-chain disease. Immunofluorescent studies of jejunal mucosa again showed a remarkable depletion of lamina propria cells staining for IgA. IgM- and IgG-containing cells, however, were present but their numbers seemed reduced.

\section{TREATMENT AND PROGRESS}

Shortly after admission signs of intestinal obstruction developed. Intravenous cyclophosphamide $(100-200 \mathrm{mg}$ daily) was given together with an initial five-day course of prednisone $(60 \mathrm{mg}$ daily). One month later his weight had increased by $3 \mathrm{~kg}$, vomiting and abdominal pain had stopped, and diarrhoea was markedly decreased. Abnormal plasma cells disappeared from peripheral blood and daily faecal fat outpurt decreased from $21.4 \mathrm{~g}$ to $13.2 \mathrm{~g}$. During this period he needed potassium supplements to treat hypokalaemia and polyuria.

In May 1971 the patient returned to Athens. He was admitted to the Hippokration Hospital, where his severe hypokalaemia and polyuria needed intensive replacement therapy. Some diarrhoea persisted but after the addition of oral Sigmamycin (tetrocycline and oleandomycin) $1 \mathrm{~g}$ daily to oral cyclophosphamide therapy he further improved and his diarrhoea ceased. He rapidly gained weight ( $23 \mathrm{~kg}$ over three months), and his finger clubbing disappeared. Over the next 10 months oral cyclophosphamide 100 $\mathrm{mg} /$ day and intermittent oral antibiotic therapy were continued. By July 1971 the patient was symptom free and was able to resume full-time employment. Radiological examination of the small intestine in December 1971 showed a more normal mucosal pattern, but a nodular appearance was still evident.

In June 1972, 15 months after diagnosis of alpha-chain disease and the start of cyclophosphamide and antibiotic therapy, the patient stopped all trearment. Since then complete clinical remission has been maintained. In August 1972 the small intestinal biopsy appearances showed marked improvement, while in February 1973 the villi were of normal height and the cell population in the lamina propria was normal (fig. 4). The immunological abnormalities also completely regressed (fig. 5). Normal IgAproducing cells were now shown in the small intestinal mucosa by immunofluorescence. Complete remission was still maintained in November 1973, 12 months after all treatment ended.

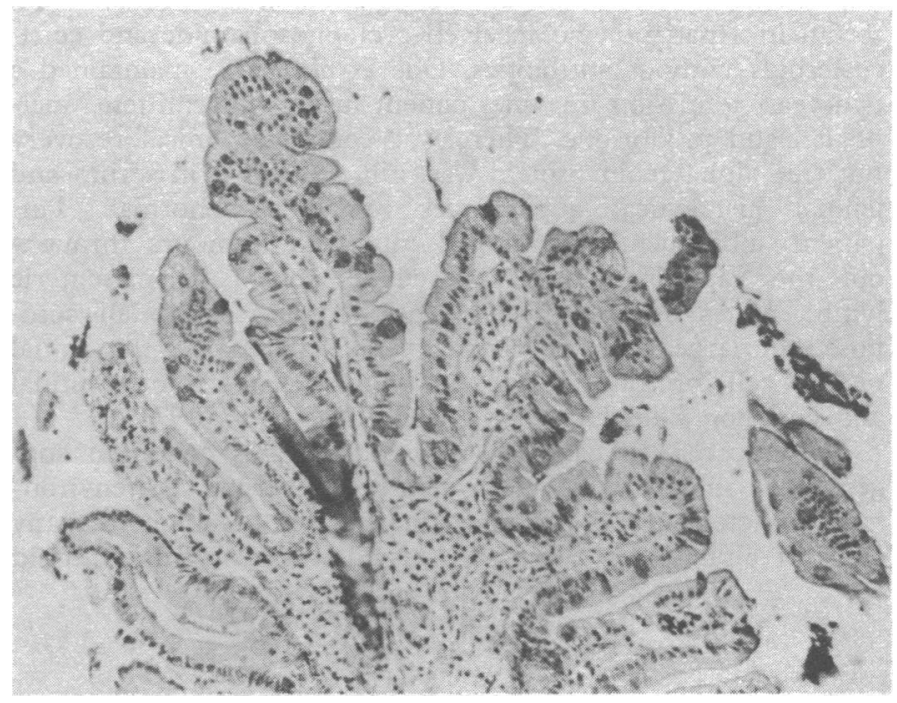

FIG. 4-Post-treatment jejunal biopsy showing normal villous architecture and normal cellular population of the lamina propria $(x 60)$.

\section{Discussion}

In this patient with alpha-chain disease there was clinical remission and disappearance of the severe histological and immunological abnormalities after cytotoxic and antibiotic 
therapy. This apparently complete remission was maintained 12 months after the end of treatment.

There are few reports of successful treatment in alphachain disease. Rogé et al. (1970) described a striking histo-

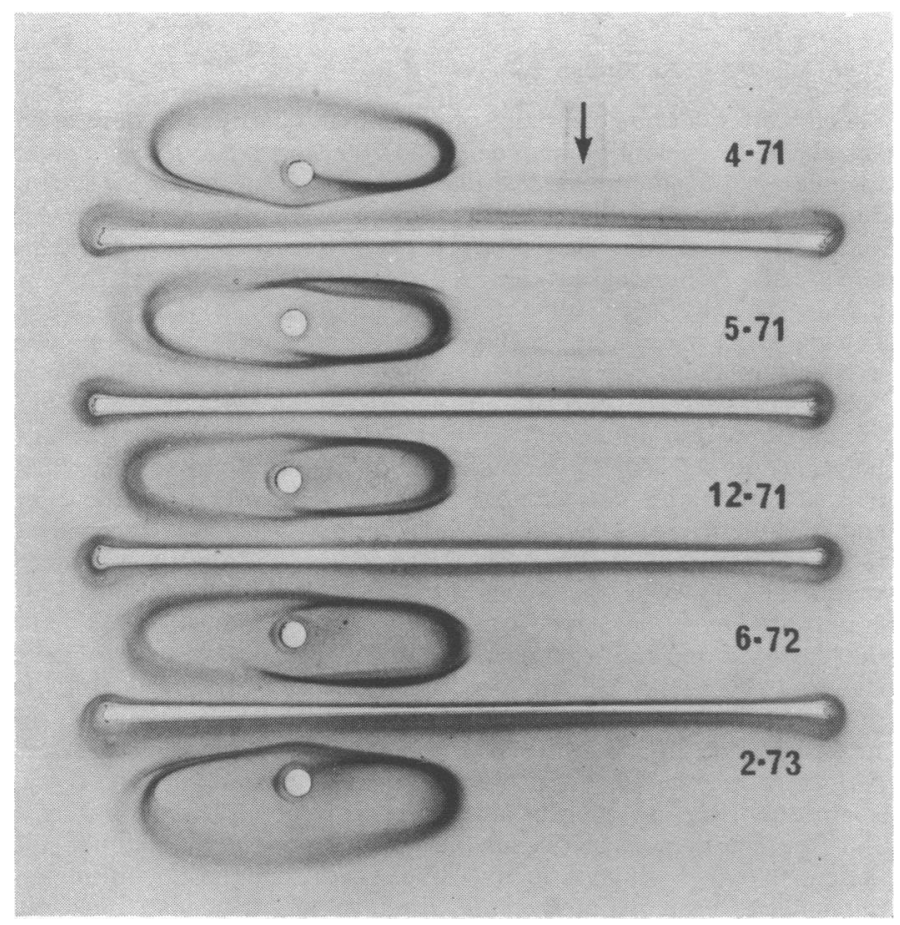

FIG. 5-Immunoselection plate showing disappearance of free alpha-chain protein (arrowed) from serum after treatment. After eight months of therapy (12-71) no free alpha-chain protein was detected.

logical and immunological recovery after 10 months of treatment with antibiotics alone. A further two patients have responded to antibiotic therapy but one subsequently relapsed (Seligmann, 1973). Zlotnick and Levy (1971) reported clinical improvement and disappearance of alpha-chain protein from serum in a patient who received cyclophosphamide and conticosteroids without antibiotics. Doe et al. (1972) maintained a two-year remission in one patient using intermittent melphalan and prednisone. There was complete clinical recovery but free alpha-chain protein was still detectable in serum and jejunal histological appearances remained abnormal. This patient subsequently developed multifocal tumours throughout the gastrointestinal tract which spread to mesenteric lymph nodes. Microscopically these tumours were all composed of large atypical plasma cells different to the initial plasma cell infiltrate. The patient finally died from intestinal and common bile duct obstruction (Doe et al., 1974).

The apparent efficacy of antibiotics in this condition suggests that an infectious agent may be concerned. An environmental factor of poor hygiene seems to be common to many cases of alpha-chain disease. Ingested micro-organisms could cause chronic sustained antigenic stimulation of the secretory IgA system in the intestine, possibly resulting in the malignant transformation of previously normal IgA-producing cells or proliferation of a pre-existent abnormal clone. In either instance broad-spectrum antibiotics could remove microorganisms responsible for the intense stimulation of the intestinal secretory IgA system. Antibiotic therapy alone might be expected to be of most benefit in early stages of the disease when the plasma cell infiltrate is confined to the lamina propria of the intestine.

The presentation of this patient with hypogammaglobulinaemia, malabsorption, and a nodular mucosal appearance on barium follow-through examination emphasizes the need to distinguish alpha-chain disease from the syndrome of hypogammaglobulinaemia and nodular lymphoid hyperplasia. Serum IgM and IgG are usually depressed in alpha-chain disease patients, and IgA levels which cannot be accurately measured using standard techniques (Doe et al., 1972) are usually high. The low IgA value recorded in our patient might have been due to polymerization of free alpha-chain protein with consequent failure to diffuse from the wells of an immunodiffusion plate. Alternatively loss of plasma cell differentiation may have resulted in less alpha-chain protein being secreted. In alpha-chain disease serum IgG and IgM values recover after treatment, suggesting that low pretreatment levels are due to immunosuppression rather than to any primary defect of IgG or IgM synthesis. Histologically there is no similarity between these two conditions. In alpha-chain disease there is a massive and diffuse plasma cell infiltration of the lamina propria with resulting structural abnormalities. In nodular lymphoid hyperplasia associated with hypogammaglobulinaemia, however, the basic abnormality is the presence within the lamina propria of numerous lymphoid follicles with well developed germinal centres and a virtual absence of plasma cells.

The demonstration of prolonged effectiveness of combined antibiotic and cytotoxic therapy in our patient who was suffering from an advanced stage of alpha-chain disease, with dissemination of the abnormal plasma cells, stresses the need for vigorous therapy in such patients. This recovery was fully maintained over two years after diagnosis and one year after stopping treatment. While it would be premature to claim a cure in this patient the completeness of his remission is encouraging.

\section{References}

Bognel, J. C., et al. (1972). Revue Europeénne d'Études Cliniques et Biologiques, 17,363 .

Doe, W. F., et al. (1972). Gut, 13, 947.

Doe, W. F., et al. (1972). Gut, 13, 947. . (1974). Unpublished.

Mancini, G., Carbonara, A. D., and Heremans, J. F. (1965). Immunochemistry, 2, 235.

Novis, B. H., et al. (1971). Quarterly fournal of Medicine, 40, 521.

Rambaud, J.'C., et al. (1972). Annales de Gastroentérologie et d'Hépatologie, $8,481$.

Rogé, J., Druet, Ph., and Marche, C. (1970). Pathologie et Biologie, 18, 851. Seligmann, M. (1973). Personal communication.

Seligmann, M., Danon, F., Hurez, D., Mihaesco, E., Preud'Homme, J. L. (1968). Science, 162, 1396.

Seligmann, M., Mihaesco, E., and Frangione, B. (1971). Annals of the New York Academy of Sciences, 190, 487.

Wieme, R. J., (1965). Agar Gel Electrophoresis, Elsevier, Amsterdam.

Zlotnick, A., and Levy, M. (1971). Archives of Internal Medicine, 128, 432. 